\title{
Responsible Leadership: Review and Prospects
}

\author{
Yang Shi, Maolin Ye \\ School of Management, Jinan University, Guangzhou, China \\ Email: sy2sun@163.com
}

Received 15 July 2016; accepted 12 August 2016; published 15 August 2016

Copyright (C) 2016 by authors and Scientific Research Publishing Inc.

This work is licensed under the Creative Commons Attribution International License (CC BY). http://creativecommons.org/licenses/by/4.0/

c) (i) Open Access

\begin{abstract}
The responsible leadership has gained considerable attention in contemporary management scholarship. As a new leadership theory, responsible leadership transcends traditional dyadic leader-subordinate relationship, and focuses on a full-range view of leader-stakeholder relationship, which can effectively deal with new challenges from all sectors of society. In this paper, we first provide an overview of the conception, structure, and measurement of responsible leadership. Besides, we analyze and conclude the antecedents and consequences of responsible leadership. Finally, we put forward some suggestions about future research in this field.
\end{abstract}

\section{Keywords}

Responsible Leadership, Stakeholder, Corporate Social Responsibility, Leadership Ethics

\section{Introduction}

In recent years, corporate scandals and managerial misconduct have been prevalent in media headlines such as tainted milk powder. As a consequence, the ethics and responsibilities of leaders have been attached much importance. Given this, Maak and Pless propose that leader as a key manager of organizations should change traditional management concept of shareholder primacy, actively care about all stakeholders inside and outside organization to fulfill corporate social responsibility [1]. However, present leadership theory such as transformational leadership, servant leadership, authentic leadership and ethical leadership mainly focuses on dyadic supervisor-subordinate relationship, but considerably ignores the influence of leaders' behaviors and decisions on other stakeholders, so these leaderships sometimes can't meet all other stakeholders' interest well except shareholders' interest. Under the background, some scholars propose the concept of responsible leadership from the stakeholder perspective [1]. As a new leadership theory, responsible leadership makes up the deficiencies of existing leadership theories, and can effectively balance the conflicting interests among stakeholders inside and 
outside organization [1] [2], thereby contributing to promoting corporate reputation, earning trust of the public and achieving sustainable development of organization and society [3].

Accordingly, responsible leadership becomes frontier research in the field of leadership and has been paid much attention. This paper first discusses and clarifies different conceptions of responsible leadership. Second, we summarize its structure, measurement, antecedents and consequences. Third, we analyze and explain how responsible leadership influences employees and organization. Based on the above analysis, we highlight directions for future research on responsible leadership.

\section{The Concept of Responsible Leadership}

At present, Chinese and overseas scholars have understood and defined responsible leadership from stakeholder theory, but there are still some differences among these definitions. This paper clarifies these conceptions and provides a new understanding.

In relation to responsible leadership, the earlier researches are conducted by Maak and Pless [1] [2]. Maak and Pless understand responsible leadership as a relational and ethical phenomenon, which occurs in social processes of interaction with all relevant stakeholders [1] [2]. That is, responsible leadership weighs and balances diverse claims from all stakeholders in accordance with the code of ethics, then makes efforts to build and maintain lasting and trustful relationships with stakeholders, aiming to achieve sustainable development of corporate and society. In order to have a better understanding of responsible leadership, Maak and Pless provide a role model that presents how responsible leadership fulfills corporate social responsibility by playing different roles. In line with Maak and Pless, Chinese scholar Song and colleagues offer similar definition that responsible leadership is aimed at building mutually beneficial relationships with stakeholders inside and outside organization through carrying out corporate social responsibility actively, in order to realize mutual benefits and shared goals [4].

However, Maak, Pless and Song just emphasize the relationship is the core of responsible leadership, relatively neglecting the significance of leadership ethics. Give that, Voegtlin further explores the connotation of leadership ethics and considers discourse ethics and deliberative democracy as the philosophical foundation of leadership ethics, and puts forward the procedural conception of responsible leadership [3] [5]. Voegtlin understands responsible leadership as a process to mediate the confliction of interests of all stakeholders by the process of equal dialogue and democratic consultation to achieve mutual benefits [3] [5]. Furthermore, Voegtlin elaborates how responsible leadership to act in that process: first, leaders should consider the consequences of one's actions for all stakeholders; second, they use their influence to provide the arenas for discursive conflict resolution and invite the affected stakeholders to join the discourse; finally, they weigh the arguments and balance the interests of the stakeholder claims to achieve a consensus [3] [5].

Based on the above analysis, we conclude that responsible leadership is the integration of leadership ethics and corporate social responsibility, aiming to be responsible for organization and stakeholders. In particular, leadership ethics are the inherent requirement of responsible leadership which require leaders adhere to ethical principles to act ethically and make ethical decisions. And, corporate social responsibility is the external requirement of responsible leadership which requires leaders broaden their view from leader-follower relationship to leader-stakeholder relationship and fulfill social responsibility. In conclusion, we hold that only bridging the individual level of leadership responsibility and the organizational level of corporate responsibility can leaders become a responsible leadership.

\section{The Structure and Measurement of Responsible Leadership}

With respect to the structure of responsible leadership, scholars hold different opinions and have not yet reached agreement. So, by analyzing different opinions, this paper puts forward some suggestions for improvements.

Voegtlin thinks responsible leadership is a continuum concept, ranging from irresponsible leadership to the responsible leadership [5]. According to this, Voegtlin develops a scale of responsible leadership consisting of five items, and further validates the discriminant, convergent and predictive validity. This scale is used to measure responsible leadership through employees reporting the frequency of interaction with stakeholders and leaders' actions or decisions.

However, most scholars consider responsible leadership as a construct of multi-dimension structure. Indeed, compared to single dimension, multi-dimension structure can interpret the connotation of responsible leadership better and more comprehensively. Doh and Stumpf argue that responsible leadership consists of three key com- 
ponents such as values-based leadership, ethical decision-making and quality stakeholder relationships [6]. Likewise, Lynham and Chermack hold the view of three dimensions that responsible leadership is composed of ethics, effectiveness and endurance [7]. Besides, Doh and colleagues propose responsible leadership is composed of three dimensions such as stakeholder culture, resource management practices and managerial support [8]. Further, on the basis of their understanding, Doh and colleagues develops a responsible leadership scale including 13 items. In this scale, there are 4 items for stakeholder culture, 5 items for resource management practices and 4 items for managerial support [8]. Through a synthesis of prior research, Stahl and Sully de Luque, from the behavioral perspective propose that responsible leadership includes the two dimensions of "do good behaviors" and "avoid harm behaviors" which are conceptually distinct from one another [9]. "do good behaviors" are the reflection of prescriptive morality, referring to behaviors aimed at enhancing societal welfare, while "avoid harm behaviors" are the reflection of proscriptive morality, referring to behaviors aimed at avoiding harmful consequences for stakeholders and larger society. Unlike the above studies, Chinese scholar Lu explores the structure of responsible leadership in Chinese context, concluding that responsible leadership is a four dimensions construct, including moral integrity, open communication, guidance and care, and active citizenship behavior [10].

Taken together, the extant researches on structure and measurement of responsible leadership are very few, which considerably limits the empirical research. Moreover, present researches exist the following deficiencies: First, there is still great disagreement about structure of responsible leadership, which greatly prevents from developing a relatively universal scale; Second, existing scales evaluate responsible leaders only by employees, ignoring leader's self-assessment and other stakeholders' evaluation. Thus, it is urgent and necessary to clarify the structure of responsible leadership and develop a standardized scale in the future.

\section{The Antecedents and Consequences of Responsible Leadership}

\subsection{The Antecedents of Responsible Leadership}

\subsubsection{Personal Factors}

Present researches show that personal traits, such as relational intelligence, empathy, cognitive moral development, Machiavellianism, play an important role in the formation and development of responsible leadership. In order to have a clear understanding of responsible leadership, this paper will describe how these personal traits influence responsible leadership in detail.

1) Relational Intelligence. In a stakeholder society, the core task of responsible leadership is to build and maintain trustful relationship with stakeholders [1]. At the same time, globalization makes leaders confront with heterogeneous stakeholders. In this context, leaders need have strong social abilities and skills to cope with different stakeholders. So, relational intelligence is an important influential factor for responsible leadership, which includes emotional intelligence and ethical intelligence [1]. On one hand, leaders with high emotional intelligence are good to control and use their own emotion and understand others' emotion, thereby effectively dealing with complex relationships. On the other hand, leaders with ethical intelligence are more inclined to walk the talk, manage with integrity, make "profits with principles", which contribute to building trustful relationship with stakeholders. Therefore, Maak and Pless emphasize that relational intelligence is a necessary ability for responsible leadership [1].

2) Empathy. Empathy refers to the ability to experience and understand others' emotion from others standpoint [11]. Leaders with empathy are more likely to concern for stakeholders. According to this, Stahl and De Luque propose that empathy can predict whether a leader is a responsible leadership in some extent [9]. Besides, Stahl and De Luque explain that a leader with empathy can understand stakeholders' opinions and needs well and know what to do to meet stakeholders' demands, thereby easily becoming a responsible leadership [9]. Related researches also provide the evidence for the view. For example, leaders with empathy are prone to engage in charity and behave responsibly [12]; likewise, leaders with empathy are more likely to make ethical decisions and be responsible for their employees [13].

3) Cognitive Moral Development. The theory of cognitive moral development shows that with the development of cognitive moral, individuals will improve their ability of moral judgement and moral decision, so in the face of moral dilemma, they know how to solve ethically [14]. It implies that, facing moral problems, leaders with high cognitive moral development will propose ethical solutions that accepted by all stakeholders. As for responsible leadership, how to make ethical decisions is a great challenge in the face of conflicting interests 
from different stakeholders. So, Maak contends that high cognitive moral development can help responsible leadership to deal with moral problems [2]. Besides, Stahl and De Luque propose that cognitive moral development is closely related with the "do good behaviors" and "avoid harm behaviors" of responsible leadership [9].

4) Machiavellianism. Many researches have demonstrated that personality traits have an important effect on people's behaviors. Machiavellianism, as a special one of personality traits, has been proved to be a negative factor for responsible leaderships. For instance, Christie and Geis hold the view that Machiavellianism reflects a predisposition to take advantage of someone else to achieve personal interests without considering someone else's interests, and leaders with Machiavellianism tend to distrust and control others, disregard ethical principles [15]. So, we can conclude that it's difficult for leaders with Machiavellianism to build friendly relationship with stakeholders, let alone be responsible for stakeholders. Moreover, a case survey conducted by Miska, Stahl, and Fuchs of 52 real cases of unethical managerial behavior reveals that companies involved in major scandals, such as Enron, WorldCom, and Salomon Brothers, are more likely to have leaders who exhibit Machiavellian traits [16].

\subsubsection{Situational Factors}

Expect personal factors, situational factors also have great influence on responsible leadership. Through the overview and synthesis of existing research on responsible leadership, we conclude that moral intensity, cultural value orientations, institutional context and media affect leaders' propensity to become a responsible leadership.

1) Moral Intensity. Moral intensity is brought forward in the research on corporate moral decisions, which fully reflects the "the extent of issue-related moral imperative in a situation" [17]. Moral intensity includes six dimensions such as social consensus, magnitude of consequences, temporal immediacy, probability of effect, proximity and concentration of effect [17]. So, moral intensity contributes to explaining why leaders may behave responsibly in some situations and irresponsibly in others. From the point of view, Stahl and De Luque contend that moral intensity influence leaders' responsible behaviors [9].

2) Cultural Value Orientations. In the researches on the relationship between cultural values and leaders' responsibility, collectivism and power distance have been paid much attention. For example, Stahl and De Luque through documentary analysis propose that collectivism and power distance are closely related with the responsible behaviors of responsible leadership [9]. Besides, some scholars have explored the relationship between corporate social responsible of leaders and cultural value orientations such as collectivism and power distance, finding that in the countries with high collectivism and low power distance, leaders tend to behave responsibly, for instance, considering the interest of shareholder, employees and other stakeholders [18]. Most importantly, this research suggests that collectivism may prompt leaders to think about how their behaviors and decisions influence a wider range of stakeholders and society while power distance may motivate leaders to concern for the interests of shareholders, employees and customers. Also, the research conducted by Dugan and colleagues support this view [19]. Dugan and colleagues have examined the influence of collectivism and individualism on responsible leadership, showing that collectivism accord with the connotations of responsible leadership and encourage leaders to become more responsible [19]. In conclusion, culture value orientations such as collectivism and power distance exert an influence on leaders' responsible behaviors.

3) Institutional Context. Institutional context have an important effect on responsible leadership [9]. In some extent, institutional context determines what is considered to be responsible and ethical, so can shape and influence the leaders' cognition of what is responsible and ethical. For instance, related empirical research has proved that if leaders perceive that corruption is popular and common in the host country, they are prone to accept and engage in the corruption even if they personally disagree with those actions [20]. However, if the host country has perfect and rigorous institutional system to forbid and sanction corruption, leaders tend to conform to the institutional system and engage in responsible behaviors. This means that sound institutional system can prevent leaders from behaving unethically.

4) Media. With the popularity of media, it becomes easier and quicker for the public to know the information about companies. In this condition, leaders gradually realize once corporate scandals are reported, the public will be informed of these bad organizational practices quickly, thereby seriously damaging the reputation of organizations. Therefore, in order to build trust and gain reputation, leaders will be responsible for the stakeholders inside and outside organizations. That is, under the supervision of media, leaders tend to become more responsible. Besides, existing research has examined the relationship between media and leaders' responsible behaviors, and proved that media can impel leaders to engage in the responsible behaviors [21]. 


\subsection{The Consequences of Responsible Leadership}

With regard to the consequence of responsible leadership, this paper respectively analyzes and describes the consequences from the individual level and the organizational level.

\subsubsection{The Consequence of Individual Level}

1) Turnover Intention. Responsible leadership can reduce the turnover rate of employees [8]. In the research of 4,352 employees from 28 companies, Doh and colleagues have investigated the relationship between responsible leadership and turnover intention [8]. They find that responsible leadership is significantly correlated with turnover intention, and further employee satisfaction can mediate the relationship between responsible leadership and employee turnover intention [8]. Most importantly, this research suggests that responsible leadership concerns for stakeholders, treats employees fairly and provides support for employees, thereby helping to attract and retain employees, which has an important practical significance.

2) Job Satisfaction. Job satisfaction refers to employees' positive attitudes and emotions towards their job after evaluating their work or work environment. Responsible leadership cares about employees' demands and interests, provides the rights to engage in organizational decisions, which make employees have good evaluations towards their work or work environment, so responsible leadership can exert positive influence on job satisfaction. For example, several empirical studies have shown that responsible leadership is positive related with job satisfaction [5] [8].

3) Organizational Commitment. Responsible leadership can motivate and promote employees' organizational commitment [3] [22]. Related researches explore the relationship between responsible leadership and organizational commitment based on social exchange theory, and further, contend that responsible leadership concerns for employees, in return, employee will work with positive job attitudes, for example, increasing organizational commitment [3] [22].

4) Unethical Behaviors. Unethical behaviors usually refer to some behaviors which can't be recognized and accepted by the public [23]. Voegtlin argues that responsible leadership can reduce the unethical behaviors of employees [5]. And, this view can be explained through social learning theory. First, Responsible leadership emphasizes leader ethics and behaves according to ethical principles, thereby provides an ethical role model for employees. Besides, in the organization, employees usually consider leaders as their role models and learn from leaders. Collectively, responsible leadership can shape and enhance the ethical behaviors of employees by means of role model.

5) Work Performance. Responsible leadership has a positive effect on work performance of employees. In the research conducted by Chen, he has investigated the relationship between responsible leadership and work performance in Chinese context, finding that responsible leadership can motivate employees to work hard and enhance performance [24]. Similarly, Voegtlin and colleagues also hold the same view, and explain that responsible leadership concerns for all stakeholders, thereby building a positive role model for employees [3]. So, employees will learn from leaders and actively engage in what is requested from the organization or job description. That is, responsible leadership can enhance extra-role performance of employees via role model.

\subsubsection{The Consequence of Organizational Level}

1) Organizational Performance. Some scholars propose that responsible leadership can motivate all stakeholders to strive for the shared goals, thereby enhancing the financial performance of organization and achieve social goals [3]. Besides, Lu has examined how responsible leadership affects organizational performance in Chinese companies, and found that responsible leadership not only has a direct effect on organizational performance, but also increases organizational performance by the mediating role of social capital [10]. Moreover, Doh and Quigley through theory analysis and case study conclude that responsible leadership can through two specific pathways including a psychological pathway and a knowledge-based pathway to influence organizational performance [22].

2) Legitimacy of the Organization. For the organization, legitimacy guarantees the license to operate in a given society. Organizations with legitimacy can easily gain sustained support and resources. With regard to legitimacy, Suchman has distinguished three types: pragmatic legitimacy, moral legitimacy, and cognitive legitimacy [25]. Voegtlin and colleagues propose that responsible leadership contributes to building and maintaining legitimacy of the organization: first, responsible leadership engage in stakeholder dialogue according to dis- 
course ethics and deliberation, which informs stakeholders of the practical actions of the organization and enhance the cognitive legitimacy; second, responsible leadership can effectively enhance organizational performance and achieve social goals, thereby securing the pragmatic legitimacy; finally, responsible leadership behaves and makes decisions based on ethical principles, thereby obtaining moral legitimacy [3]. To sum up, responsible leadership can build and maintain the legitimacy of the organization.

3) Corporate Social Responsibility. Corporate social responsibility is usually understood as what organizations do in relation to social responsibility. As for responsible leadership, corporate social responsibility is the essential connotation of responsibility. Furthermore, responsible leadership is put forward to deal with the frequent happening corporate scandals and fulfill the corporate social responsibility. So, responsible leadership engages in social responsible activities actively, for example, providing comfortable working environment for employees, producing healthy and safe foods for customers, cooperating with partners fairly and honestly, saving resources and protecting environment. Through these practical actions, responsible leadership tries to fulfill corporate social responsibility. Also, a case study has proved that responsible leadership help to fulfill social responsibility by the means of concerning for all stakeholders such as community, government, environment, customers and so on [4].

\section{Conclusion and Future Research}

Throughout the reviewing of existing research on responsible leadership, we propose that responsible leadership can deal with conflicting interests of different stakeholders well, so it's of great significance to further study in this field. However, the field of responsible leadership is still in its infancy, and some questions on the topic remain in high demand.

\subsection{The Indigenization Research on Responsible Leadership}

Present researches on responsible leadership are conducted in western countries. In view of culture diversity, how and what Chinese culture influence responsible leadership still need to be further explored. Compared to western countries, China emphasizes collectivism. Therefore, in this context, the structure of responsible leadership may be different. Besides, Chinese people have the special national traits which emphasize "Renqing" and "Guan Xi", so, they are prone to distribute benefits based on the intimacy of "Guan Xi", which sometimes goes against the ethical principles and damages interests of other stakeholders. But responsible leadership contends that leaders should weigh and balance interests of all stakeholders according to ethics. In the face of the difference, responsible leadership should how to deal with to achieve the goal of localization. Finally, future research needs to develop a responsible leadership scale in Chinese context. In short, the indigenization of responsible leadership can not only broaden the scope of application of responsible leadership, but also enrich the theory.

\subsection{The Research on Mediating Effect Based on Social Identity Theory}

According to Social identity theory, when employees have identified the leaders or organizations, they will do much good to organization. First, responsible leadership has good moral quality and cares about employees, which may contribute to improving supervisor identification of employees. Moreover, some researches provide the evidence that corporate social responsibility and organizational support can promote employee's organizational identity [26] [27]. From the point of view, responsible leadership actively fulfills corporate social responsibility, so we can deduce that responsible leadership may have positive effects on organizational identity. Above the analysis, we can deduce that responsible leadership can affect employees and organization by the mediating role of supervisor identification and organizational identification. However, this is just theoretical analysis and has yet to be confirmed in the future.

\section{References}

[1] Maak, Th. and Pless, N.M. (2006) Responsible Leadership in a Stakeholder Society-A Relational Perspective. Journal of Business Ethics, 66, 99-115. http://dx.doi.org/10.1007/s10551-006-9047-z

[2] Maak, T. (2007) Responsible Leadership, Stakeholder Engagement and the Emergence of Social Capital. Journal of Business Ethics, 74, 329-343. http://dx.doi.org/10.1007/s10551-007-9510-5 
[3] Voegtlin, C., Patzer, M. and Scherer, A.G. (2012). Responsible Leadership in Global Business: A New Approach to Leadership and Its Multi-Level Outcomes. Journal of Business Ethics, 105, 1-16. http://dx.doi.org/10.1007/s10551-011-0952-4

[4] Song, J.W., Sun Z.Q. and Wei, J.F. (2009) Responsible Leadership and the Establishment of Corporate Social Capital: A Case Study of Yihai. Chinese Journal of Management, 6, 988-944.

[5] Voegtlin, C. (2011) Development of a Scale Measuring Discursive Responsible Leadership. Journal of Business Ethics, 98, 57-73. http://dx.doi.org/10.1007/s10551-011-1020-9

[6] Doh, J.P. and Stumpf, S.A. (2005) Towards a Framework of Responsible Leadership and Governance. In: Doh, J.P. and Stumpf, S.A., Eds., Handbook on Responsible Leadership and Governance in Global Business, Edward Elgar, Cheltenham, 3-18. http://dx.doi.org/10.4337/9781845425562.00007

[7] Lynham, S.A. and Chermack, T.J. (2006) Responsible Leadership for Performance: A Theoretical Model and Hypotheses. Journal of Leadership and Organizational Studies, 12, 73-88. http://dx.doi.org/10.1177/107179190601200405

[8] Doh, J.P., Stumpf, S.A. and Tymon Jr., W.G. (2011) Responsible Leadership Helps Retain Talent in India. Journal of Business Ethics, 98, 85-100. http://dx.doi.org/10.1007/s10551-011-1018-3

[9] Stahl, G.K. and de Luque, M.S. (2014) Antecedents of Responsible Leader Behavior: A Research Synthesis, Conceptual Framework, and Agenda for Future Research. The Academy of Management Perspectives, 28, 235-254. http://dx.doi.org/10.5465/amp.2013.0126

[10] Lu, Y.H. (2012) The Impact of Responsible Leadership on Business Growth Performance: Base on the View of the Stakeholder Theory. MA Dissertation, Zhejiang University, Hangzhou.

[11] Decety, J., Philip, L. and Jackson, P.L. (2006) A Social-Neuroscience Perspective on Empathy. Current Directions in Psychological Science, 15, 54-58. http://dx.doi.org/10.1111/j.0963-7214.2006.00406.x

[12] Muller, A.R., Pfarrer, M.D. and Little, L.M. (2014) A Theory of Collective Empathy in Corporate Philanthropy Decisions. Academy of Management Review, 39, 1-21. http://dx.doi.org/10.5465/amr.2012.0031

[13] Dietz, J. and Kleinlogel, E.P. (2014) Wage Cuts and Managers’ Empathy: How a Positive Emotion Can Contribute to Positive Organizational Ethics in Difficult Times. Journal of Business Ethics, 119, 461-472. http://dx.doi.org/10.1007/s10551-013-1836-6

[14] Kohlberg, L. (1984) The Psychology of Moral Development: Essays on Moral Development. Harper \& Row, San Francisco.

[15] Christie, R. and Geis, F.L. (1970) Studies in Machiavellianism. Academic Press, New York.

[16] Miska, C., Stahl, G.K. and Fuchs, M. (2014) Unethical Managerial Behavior: The Moderating Roles of Moral Intensity and Situational Strength. The 74th Annual Meeting of the Academy of Management, Philadelphia, 1-5 August 2014, 13531. http://dx.doi.org/10.5465/ambpp.2014.13531abstract

[17] Jones, T.M. (1991) Ethical Decision Making by Individuals in Organizations: An Issue-Contingent Model. Academy of Management Review, 16, 366-395.

[18] Waldman, D.A., de Luque, M.S., Washburn, N., House, R.J., Adetoun, B., Barrasa, A., et al. (2006) Cultural and Leadership Predictors of Corporate Social Responsibility Values of Top Management: A GLOBE Study of 15 Countries. Journal of International Business Studies, 37, 823-837. http://dx.doi.org/10.1057/palgrave.jibs.8400230

[19] Dugan, J.P., Morosini, A.M.R. and Beazley, M.R. (2011) Cultural Transferability of Socially Responsible Leadership: Findings from the United States and Mexico. Journal of College Student Development, 52, 456-474. http://dx.doi.org/10.1353/csd.2011.0052

[20] Collins, J.D., Uhlenbruck, K. and Rodriguez, P. (2009) Why Firms Engage in Corruption: A Top Management Perspective. Journal of Business Ethics, 87, 89-108. http://dx.doi.org/10.1007/s10551-008-9872-3

[21] Zyglidopoulos, S.C., Georgiadis, A.P., Carroll, C.E. and Siegel, D.S. (2012) Does Media Attention Drive Corporate Social Responsibility? Journal of Business Research, 65, 1622-1627. http://dx.doi.org/10.1016/j.jbusres.2011.10.021

[22] Doh, J.P. and Quigley, N.R. (2014) Responsible Leadership and Stakeholder Management: Influence Pathways and Organizational Outcomes. The Academy of Management Perspectives, 28, 255-274. http://dx.doi.org/10.5465/amp.2014.0013

[23] Kaptein, M. (2008) Developing a Measure of Unethical Behavior in the Workplace: A Stakeholder Perspective. Journal of Management, 34, 978-1008. http://dx.doi.org/10.1177/0149206308318614

[24] Chen, L.Q. (2014) A Research on the Mechanism of Responsible Leadership Influence on Job Performance. MA Dissertation, Wuhan University of Science and Technology, Wuhan.

[25] Suchman, M.C. (1995) Managing Legitimacy: Strategic and Institutional Approaches. Academy of Management Review, 20, 571-610. 
[26] Carmeli, A., Gilat, G. and Waldman, D.A. (2007) The Role of Perceived Organizational Performance in Organizational Identification, Adjustment and Job Performance. Journal of Management Studies, 44, 972-992. http://dx.doi.org/10.1111/j.1467-6486.2007.00691.x

[27] Edwards, M.R. and Peccei, R. (2010) Perceived Organizational Support, Organizational Identification, and Employee Outcomes. Journal of Personnel Psychology, 9, 17-26. http://dx.doi.org/10.1027/1866-5888/a000007

\section{Submit or recommend next manuscript to SCIRP and we will provide best service for you:}

Accepting pre-submission inquiries through Email, Facebook, LinkedIn, Twitter, etc.

A wide selection of journals (inclusive of 9 subjects, more than 200 journals)

Providing 24-hour high-quality service

User-friendly online submission system

Fair and swift peer-review system

Efficient typesetting and proofreading procedure

Display of the result of downloads and visits, as well as the number of cited articles

Maximum dissemination of your research work

Submit your manuscript at: http://papersubmission.scirp.org/ 